\title{
Sources of Return in the Index Futures Markets
}

\author{
Adam Zaremba'
}

ABSTRACT

The paper concerns an issue of existence of a risk premium in equity and index futures markets. The paper consists of four parts. The first part describes the basic hypotheses of forward curves in the futures market. In the second section, I formulate 5 hypotheses concerning a risk premium in the equity futures market, its forecastability, and its dependence on a market segment and development stage. The third part includes an empirical study, which confirms the existence of timedependent and partially predictable risk premium. The research was based on the Polish futures market in the years 2000-2010. The last section of the paper discusses potential implications for the financial market practice and indicates areas for further research.

KEY WORDS: $\quad$ futures, risk premium, forward curve

JEL Classification: $\quad$ G13, G14, G17

1 Poznań University of Economics, Poland

\section{Introduction}

There are a number theories accounting for the shapes of forward curves in the literature. ${ }^{1}$ The oldest of these include the theory of rational expectations and the theory of normal backwardation - the hedging pressure hypothesis being a more flexible development of the latter theory. Although both theories are usually applied to raw materials markets, they both bring interesting consequences for financial markets and especially for index futures contracts. In the author's opinion, they can imply the existence of a risk premium, which is variable in time in the futures market. A risk premium is understood as an excess return over risk-free instruments, which are not accounted for by a traditional source of systematic risk, i.e. a change in prices in the spot market (Sherer \& He, 2008).

This article consists of four parts. In the first part, basic theories of forward curves will be described. The sec-

Corespondence concerning to this article should be addressed to: adam.zaremba@ue.poznan.pl ond part presents an analysis of potential implications of these theories for the market of index and stock futures contracts and research hypotheses concerning a timevariable risk premium. In the third part, the hypotheses are verified on the basis of the performance of 46 series of futures contracts in the index of big stock exchangelisted companies (WIG20) from February 2000 to July 2010 and 16 futures contracts on the index of mediumsized stock exchange-listed companies mWIG40. The last part discusses the implications of the observations made for the financial market practice and it shows potential directions for further research.

\section{Theories of Forward Curves}

The prices of base assets with future delivery can be higher or lower than the current prices. If the future price is higher than the spot price, this situation is called contango and the forward curve is rising. On the other hand, if future prices are below the spot price, this means that the forward curve is falling. Such a situation is called backwardation. 
There are a number of theories accounting for shapes of forward curves in the literature devoted to the subject matter. Although both theories are usually applied to raw materials markets in the classical version, some of them - under specific conditions - seem to be appropriate for stock and index futures contracts. In the author's opinion, this applies, among other things, to the theory of rational expectations, the theory of normal backwardation and the theory of hedging pressure. They will be discussed further in the text.

Theories accounting for the shape of the forward shape differ fundamentally as regards the justification of the function of the risk premium in markets. Three broad categories of theories can be distinguished. The first group included theories, according to which no systematic risk premium exists for holders of long or short positions in the futures market. The second group is the opposite of the first one, justifying a positive risk premium for holders of long or short positions. The third groups allows for conditional function of such premiums at defined time periods or market segments.

\subsection{Theories of storage}

Theories of storage focus mostly on the motivations of market participants, who use raw materials in the manufacturing process, and raw materials futures markets are for them a place to purchase raw materials or to secure their deliveries. This distinguishes them from numerous subsequent theories, which concentrated on speculators and partially explains why they were neglected in the literature concerning investments in raw materials markets.

Kaldor (1939) is considered to be the father of the theory of storage. He noticed that the possession of raw materials stocking is connected with two consequences: the costs of financing and storing such raw materials, as well as benefits resulting from the possibility of using the stock in the case of such a business need. The first of the afore-mentioned components was later called the cost of carry, while the other was dubbed as convenience yield.

Kaldor (1939) presented the following equation in his work:

future - spot $=$ storage costs + interest costs - convenience benefit

The equation above, which is considered together with the continuous capitalisation, was then included in popular handbooks, e.g. Hull (1994) and Geman (2005). The theory of storage costs was later interpreted on numerous occasions (Working, 1948, 1949; Brennan, 1958; Telser, 1958, 1960; Helmuth, 1981; Brennan, 1991; Erb \& Harvey, 2006; Till, 2008), and it also became an integral component of many subsequent theories.

\subsection{Theory of rational expectations}

The theory of rational expectations assumes that the futures price is equal to the current expectations of the future spot price when the contract is executed. This theory is based on the arbitration mechanism operating in the market. Investors, who notice that the futures price is different from the expectations of the future spot price, can perform a spread transaction consists in a simultaneous purchase and sale of the base and derived instrument, thus making a profit. As a result, expectation of the low spot price in the future will be reflected by the current low futures price, while expectations concerning the high spot price in the future will be reflected in the high futures price (Black, 1976; Gorton \& Rouwenhorst, 2005).

Hicks (1939) is usually regarded as the author of the theory of rational expectations; however, Evans \& Honkapohja (2001) mention that the notion of rational expectations was also used by Hurwicz in a 1946 article.

The theory of rational expectations works very well under laboratory conditions (no transaction costs, taxes, loan limitations, neutrality of investors towards risk); however, in practice, it did not turn out very useful in accounting for forward curves (Spurgin \& Donohue, 2009, p. 124). According to the rational expectations theory, when the market is balanced there is no room for the existence of a positive risk premium for long or short position holders.

\subsection{Theory of normal backwardation}

The theory of normal backwardation, which was dealt with by, among others, Gorton \& Rouwenhorst (2001), Bodie \& Rosansky (1980) and Fama \& French (1987), was first put forward by Keynes in 1930.

According to the normal backwardation theory, manufacturers of raw materials are highly motivated to secure the sales price of goods using short positions in futures or forward contracts. It happens so, because 
knowing their own production costs in advance, they can ensure appropriate profitability in this way. On the other hand, consumers prefer to make purchases in the spot market as this offers greater flexibility to them. This situation results in a regular over-supply at a distant section of the forward curve, which is balanced by speculators taking long positions with a discount in relation to the spot price. Also consumers attracted by an advantageous discount may also decide to take long positions. According to the natural backwardation theory, a falling profitability curve is a typical situation in the market.

In accordance with Keynes's theory, the current futures price is lower than the expected spot price in the future. In such a situation, the performance of a futures contract should gradually rise, to finally become equal to the spot price on the execution day. This results in a positive return for long position holders. According to the normal backwardation theory, an additional risk premium for long position holders should be perceived as the cost of insurance against the fall of raw material prices paid by manufacturers to speculators and consumers in the market.

Normal backwardation should also affect differences in yields between various futures contracts. Markets characterised by higher normal backwardation (a higher positive difference between the expected spot price and the futures rate) should bring a higher premium for investors holding long positions. However, this thesis is difficult to prove as the expected spot rate is naturally unobservable. However, the fact of existence of long-term positive yields from long positions in single futures contracts should be a strong argument in favour of the theory proposed by Keyners (Erb \& Harvey, 2006).

\subsection{The hedging pressure hypothesis}

The hedging pressure hypothesis is a significant supplement to the normal backwardation theory. Cootner (1960), Deaves \& Krinsky (1995) and also Erb \& Harvey (2006) showed that the theory of normal backwardation assumes that the position of hedging entities is always long as far as base assets are concerned and, therefore, they always secure themselves by assuming the short position in futures contracts. As a result, the forward curve is falling and it offers a possibility of making a profit for speculators taking long posi- tions. The afore-mentioned authors imply that the risk premium can be offered both in backwardation and contango markets, depending on the fact whether the hedging entities assume long or short positions.

Anson (2000) introduces a distinction between markets dominated by manufacturers protecting their interests and consumers. For example, manufacturers of oil, who, due to the character of their activity, have a long position in the oil market, try to reduce their exposure to risk by concluding short positions on the futures market. Transactions concluded by oil producers cause the forward curve to fall and, thus, a positive risk premium arises. On the other hand, for example in the aluminium market, consumers who use aluminium in the production process can have the dominant position. To decrease the cost level fluctuation, they take long positions in futures contracts, thus causing the formation of a rising forward curve. In this case, it is the risk premium that will be attributed to speculators taking short positions. In summary, according to the hedging pressure hypothesis, both portfolios consisting of long and short positions can receive the risk premium.

Both theories - natural backwardation and hedging pressure - find room for the existence of positive risk premium in the market. It is the cost of insurance, which must be paid to speculators by hedging entities. The theory of the hedging pressure, however, is a more flexible extension of the natural backwardation theory, as it accounts for the possibility of the existence of a risk premium, regardless of the dominant position of hedging entities.

A range of proofs in favour of the hedging pressure theory is provided in the literature. Bessembinder (1992), after examining 16 various futures contracts concluded in the years 1967-1989, observed that there existed a dependency between average yields and net securing positions. Similar conclusions were drawn by De Roon, Nijman \& Veld (2000), who noticed that hedging pressure accounted well for yields resulting from $20 \mathrm{fu}$ tures contracts listed in the years 1986-1994.

\subsection{Other theories}

Apart from the theories described above, there are a number of other hypotheses in the literature, e.g. the liquidity preference hypothesis (Spurgin \& Donohue, 2009), market segmentation hypothesis (Gautier, 2005; 



\section{Research of the Polish Market of Futures Contracts}

Verification of hypotheses I-V was performed on the basis of data obtained from the Polish market. The Polish market was considered to be a proper place for the observation of a natural experiment on the following grounds:

1. The operation of a relatively liquid market of futures contracts based on stock price indices.

2. The presence of considerable short sale restrictions.

3. It is commonly regarded as an emerging market characterised by a lower informational efficiency than mature markets.

The study was based on the closing prices of 46 series of futures contracts on the index of big stock exchange-listed companies WIG20 from February 2000 to July 2010 and 16 futures contracts on the index of medium-sized stock exchange-listed companies mWIG40. All data came from the Bloomberg site and generally available informational websites: gpwinfostrefa.pl, interia.pl, etc.

\subsection{Hypothesis I: the level of the base in the stock futures market depends on future changes in the base instrument prices}

Hypothesis I was verified by measuring correlation between the current value of the base on the indices WIG 20 and WIG40 and future yields on these indices. The WIG20 index is the index of the largest and the most liquid stock exchange-listed companies, while mWIG40 represents the segment of mid-sized companies. Both of these are price indices weighted by the turnover and capitalisation. The value of the base both in this calculation and in subsequent ones was calculated as a logarithmic difference between the performance in the spot market and in the futures market according to formula (1):

$$
b_{t}=\ln \left(\frac{s_{t}}{f_{t}}\right)
$$

where: $b_{t}$ is understood as the base level on day $t, s_{t}$ means the performance of the base instrument on day $t$ (appropriately WIG20 or mWIG40) and $f_{t}$ denotes the performance of a futures contract based on the base instrument on day $t$.

If more than one series of futures contracts were available, the instrument with the closest settlement date was always used.
The base instrument yield was also calculated by means of a logarithmic approach according to formula (2):

$$
b_{t}=\ln \left(\frac{s_{T}}{s_{t}}\right)
$$

where: $T>t$.

The linear correlation was calculated using the standard Pearson's index, while it was not limited to the single yield, but the correlations with a range of other yields corresponding to various time periods were also analysed: starting from the yield at the next session to the yield over the next 250 days. For calculations pertaining to yields over periods longer than one session, the problem of overlapping yields appeared and, therefore, the significance level t was calculated using a modified number of degrees of freedom according to formula (3):

$$
t=\frac{r}{\left(1-r^{2}\right)^{0,5}} \times\left(\frac{n}{k}-2\right)^{0,5}
$$

where: $r$ is understood as the correlation coefficient, $n$ is the number of yields in a sample and $k$ is the number of days covered by the yield (for example for a four-day yield $k=4$ ).

The correlation between the future changes of the WIG20 index was historically positive. This means that the positive base was directly connected with subsequent short-term increases in the index value, while the negative base usually implied decreases in the index value. The level of statistical significance is characterised by specific "bimodality". The first maximum, amounting to 2.53 , is reached for 7 -day yields at a low correlation level $(r=0.11)$. The second maximum, amounting to 2.39 , is connected with 53-day yields, with the correlation at a level of 0.28 . Generally, correlation is positive at the statistically significant level for cases with 2- to 103-session yields. It is worth noting here that despite the existence of statistical significance, the correlation remains relatively low. It needs to be emphasised that the statistical significance should be considered noteworthy as this level is sufficient and commonly accepted for the construction of effective investment strategies in financial markets (Narang, 2009).

The analysis presented above may lead to reverse conclusions than those resulting from the rational expectations theory. Future changes of the prices of the 
Figure 1. Correlation between the base value and the future WIG20 yield (February 2000 - July 2010)

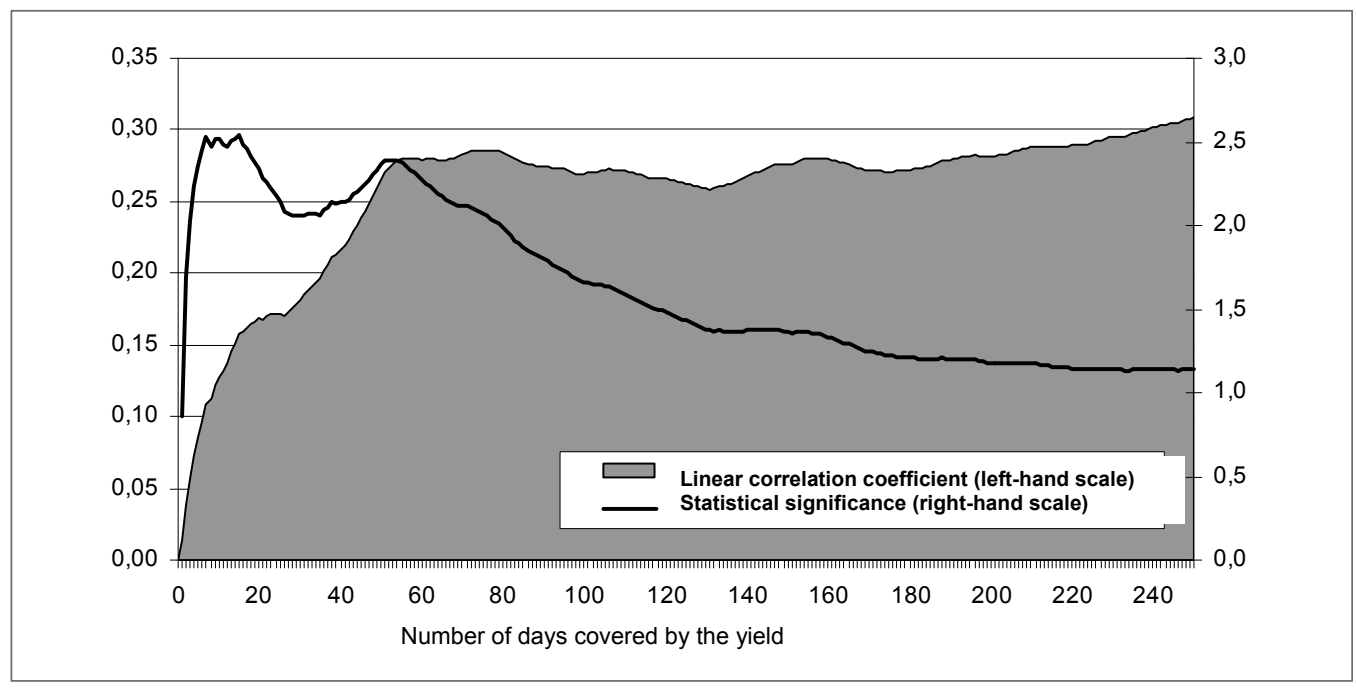

Source: own study

WIG20 index actually did contain significant information about future price movements, although the direction of the dependence is worth noting. The positive correlation means that in situations, in which the base was positive, increases usually followed and when the base was negative, decreases occurred as a result. In other words, when investors in the futures market ex- pected increases in accordance with the expectations theory, decreases usually occurred and when the market suggested that depreciation should be expected, increases frequently followed.

Figure 2 presents a sample distribution of 54-day yields $s^{2}$ according to the initial division of the base in the market.

Figure 2. 54-day WIG20 yields and the base level (February 2000 - July 2010)

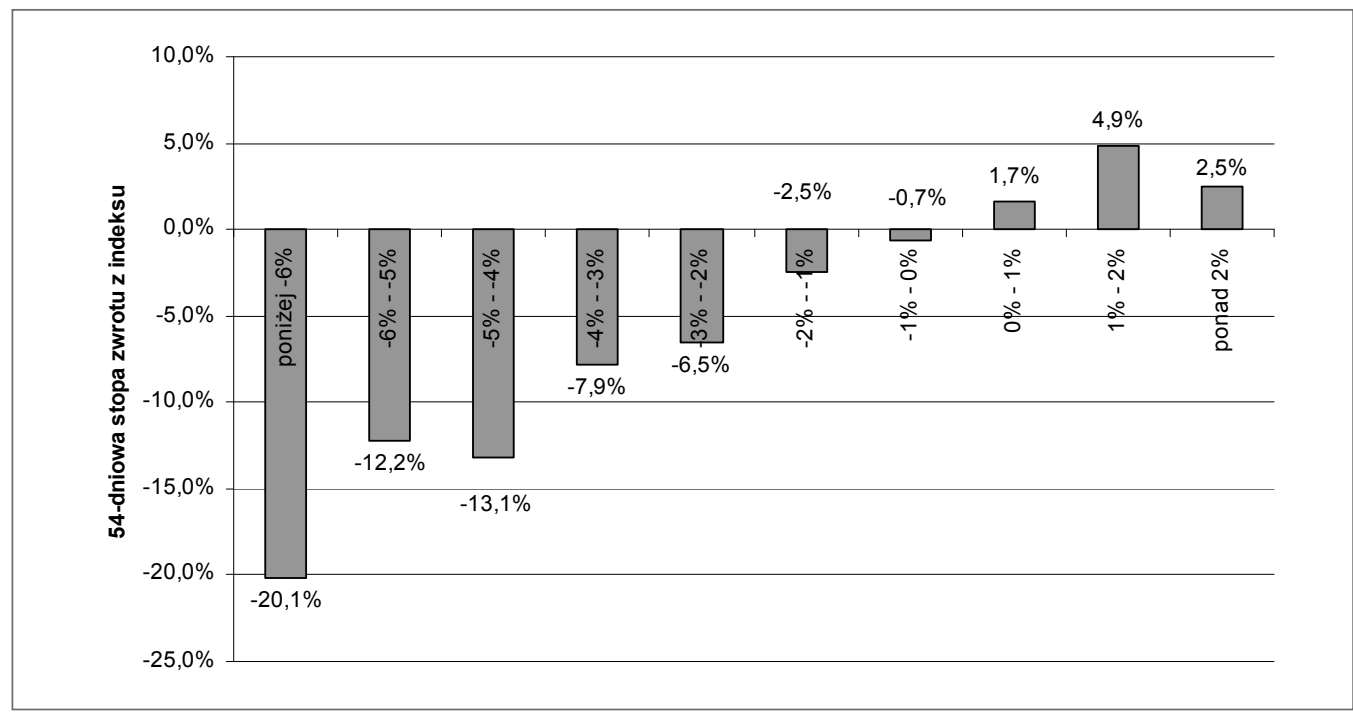


A superficial graphic analysis confirms the previous findings. The higher the increases expected by investors were, the greater depreciation followed - and the other way round - the higher the depreciation was expected, the greater the average increases occurred. Such behaviour of the investors can hardly be considered rational. In fact, we do not deal so much with the rational expectations theory here, but with the irrational expectations theory.

Considering the statistical significance of the relationship presented above, it seems that the current base level can be treated as a useful mood indicator, which makes it possible to predict future price changes in the market. It is significant to the extent, in which the dependence between the base and the future price changes cannot be accounted for by the remaining elements affecting the base level: the expected dividends and interest rates. Dividends increase the base level and then they result in index depreciation, ${ }^{3}$ which would imply negative correlation. This relationship looks analogous in the case of interest rates. High interest rates, which decrease the base level, should be associated with future index increases rather than with decreases. It so happens that, in an environment of high interest rates, their depreciation is more likely than their appreciation and this, according to the classical approach, results in higher stock values in the securities market. This status quo implies a negative correlation between the base level with future price changes of the base instrument rather than a positive one.

Similar dependence as in the case of WIG20 is also shown by mWIG40 futures contracts. Figure 3 presents a correlation between the level of the contract base based on the mWIG40 with the nearest expiry date and future yields of different lengths on this index.

Figure 3. Correlation between the base value and the future mWIG40 yield (November 2006 - JULY 2010)

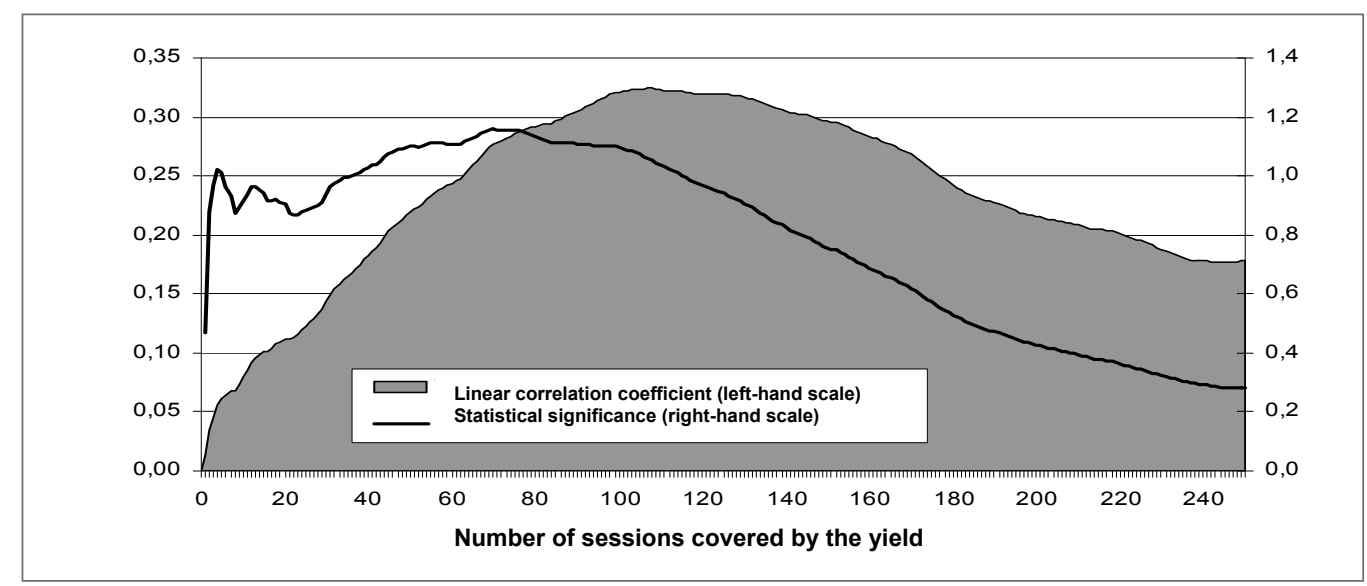

Source: own study

For mWIG40, the correlation with the future yields is equally big, and in some cases, it is even higher; however, unfortunately, it is statistically insignificant. A sample smaller than for WIG20 is a problem here. mWIG40 futures contracts have a shorter history as they have been in operation since 2006. However, the dependency in operation in the market is noteworthy. Figure 4 presents mWIG40 54-day yields (a period in which the highest correlation was observed) according to the division of the base level at the beginning of the measurement.
The calculations presented above contain valuable information, which can serve as a basis for tactical asset allocation by stock exchange investors. This research does not determine the truth of the Rational Expectations Hypothesis - on the contrary, it shows that investors' expectations are far from being rational - however, their direction can be an important indication of future price changes in the market. Full justification of the sources of the exiting dependency is beyond the scope of this publication; however, in the 

Figure 5. WIG20 futures contracts vs. companies included in the index - comparison of investments

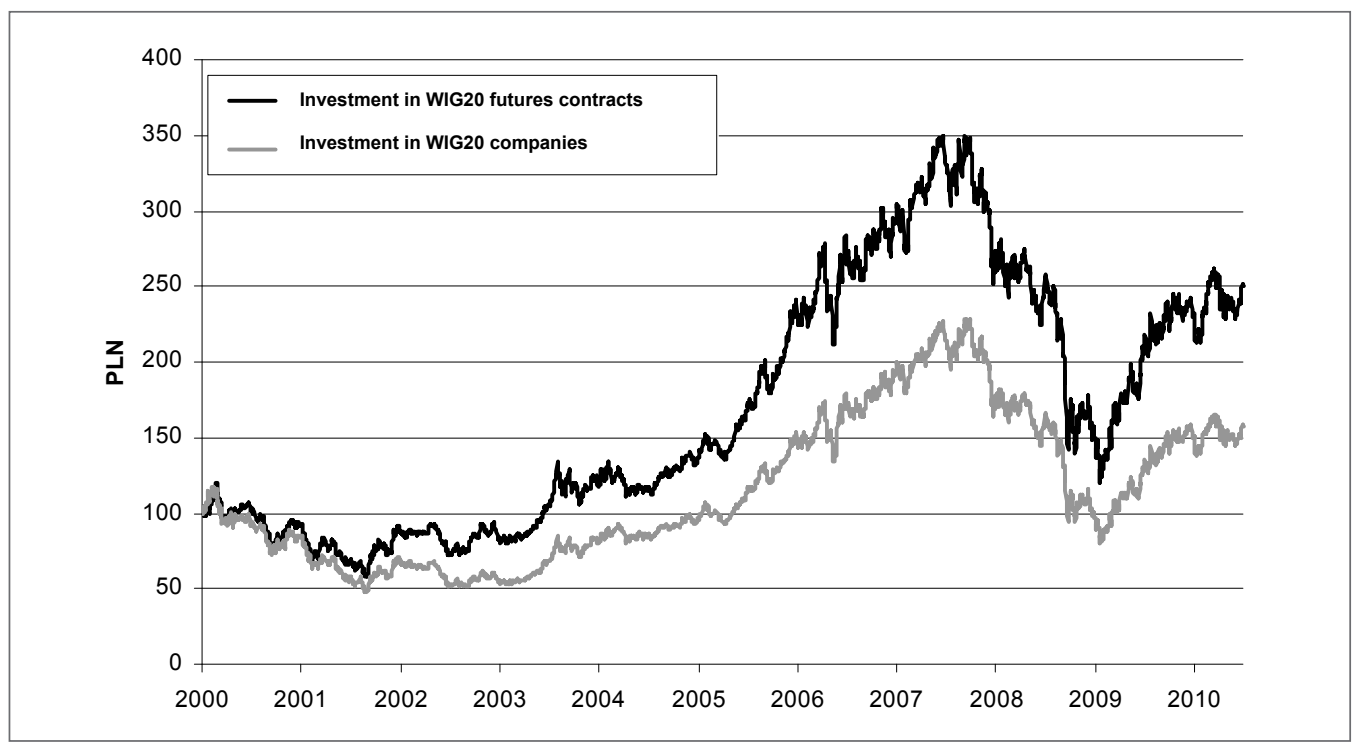

Source: own study

Table 1. WIG20 futures contracts vs. companies included in the index - comparison of income sources

\begin{tabular}{|c|c|c|c|c|c|c|}
\hline & \multicolumn{3}{|c|}{ Futures contracts } & \multicolumn{3}{|l|}{ WIG20 Companies } \\
\hline & Total yield & Collateral yield & Roll yield & Spot yield (Total yield) & Spot yield & Dividend yield \\
\hline $\begin{array}{l}\text { Total yield for the } \\
\text { period from } 2 \text { Feb } \\
2000 \text { to } 29 \text { July } 2010\end{array}$ & $152.09 \%$ & $128.73 \%$ & $-2.57 \%$ & $13.12 \% \mathbf{5 7 . 7 6} \%$ & $9.39 \%$ & $44.21 \%$ \\
\hline average annual yield & $9.22 \%$ & $8.21 \%$ & $-0.25 \%$ & $1.18 \% 4.44 \%$ & $0.86 \%$ & $3.55 \%$ \\
\hline
\end{tabular}

Source: own study

WIG20 futures contracts (February 2000 - July 2010). The analysis presents a change of the value of PLN 100 allocated according to each of the strategies in time

The investment in futures contracts was characterised by a higher yield in the period under analysis than an analogous investment in WIG20 companies. Each PLN 100 invested on 3 February 2000 into the individual strategies was worth PLN 157.76 for companies and PLN 252.09 for futures contracts on 29 July 2010. The average rate of return amounted to $9.22 \%$ for contracts and $4.44 \%$ for companies, which means a difference of 4.78 percentage points.

Table 1 presents results of both strategies divided into individual sources of income.
The difference in the average annual rates of return is statistically significant at the $5 \%$ level. ${ }^{5}$ The aforementioned calculations seem to confirm Hypothesis II concerning the existence of a positive risk premium for investors keeping long positions in futures contracts.

The afore-mentioned difference is not so significant for the mWIG40 portfolio. A study of mid-sized stock exchange-listed companies was performed in the same manner as WIG20, the only exception being the fact that a constant dividend yield at the level of $1.17 \%$ was adopted for analysis (according to Bloomberg). The study covered the period from November 2006 July 2007. The result of investment strategies based on stocks and futures contracts is presented in Fig. 6. 
Figure 6. mWIG40 futures contracts vs. companies included in the index - comparison of investments

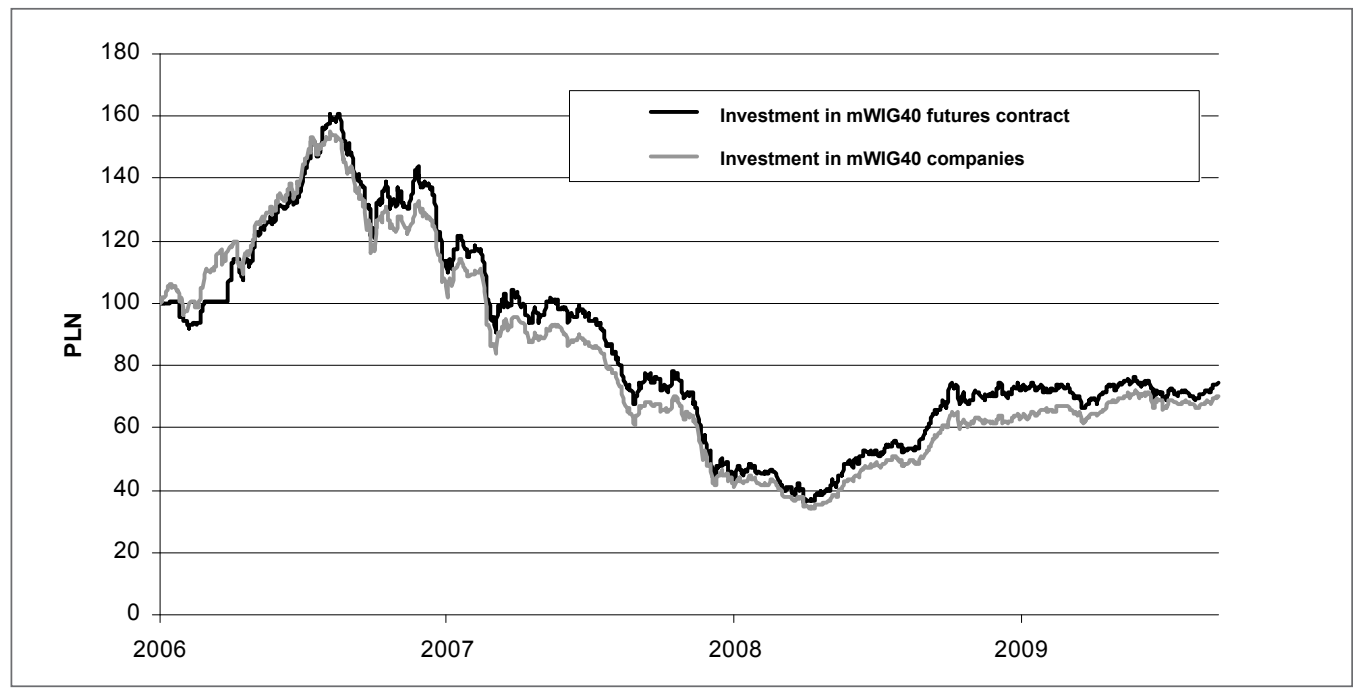

Source: own study

Table 2. WIG40 futures contracts vs. companies included in the index - comparison of income sources

\begin{tabular}{llllllll}
\hline & \multicolumn{3}{c}{ Futures contracts } & \multicolumn{2}{c}{ mWIG40 companies } & & \\
& Total yield & Collateral yield & Roll yield & Spot yield & Total yield & Spot yield & Dividend yield \\
\hline $\begin{array}{l}\text { Total yield 02 Feb } \\
\text { 2000 - 29 July 2010 }\end{array}$ & $\mathbf{- 2 5 . 6 2 \%}$ & $20.35 \%$ & $-3.82 \%$ & $\mathbf{- 3 5 . 7 4 \%}$ & $-29.87 \%$ & $-32.81 \%$ & $4.38 \%$ \\
average annual yield & $\mathbf{- 7 . 7 2 \%}$ & $5.15 \%$ & $-1.05 \%$ & $-11.31 \%$ & $-9.18 \%$ & $-10.23 \%$ & $1.17 \%$ \\
\hline
\end{tabular}

Source: own study

The value of PLN 100 invested according to the strategy described above on 21 November 2006 was reduced to PLN 74.38 for futures contracts until 29 July 2010 and to PLN 70.13 for mWIG40 companies. Both strategies caused losses. Table 2 presents results of both strategies divided into individual sources of income.

The difference in the annual yields achieved by both strategies amounted to 1.46 percentage points. This difference is positive again; however, due to the lower value than in the case of WIG20 and a shorter period covered by the study, it is statistically insignificant.

\subsection{Hypothesis III: the risk premium for long} position holders is higher for contracts, for which large companies constitute the base elements than for contracts, where small companies constitute the base instrument
The difference in the yields on futures contracts and base indexes, which was calculated for the verification of Hypothesis II, amounted to $4.78 \%$ for WIG20 and $1.46 \%$ for mWIG40. The statistical significance of this difference was verified by means of two methods: assuming normal distribution of logarithmic differences in yields between contracts and base indices and the bootstrap method, which did not require making assumptions concerning the distribution.

The significance was tested according to formula (4) using the first of the methods presented above:

$$
t=\frac{\overline{d_{W I G 20}}-\overline{d_{m W I G 40}}}{\sqrt{\frac{v_{W I G 20}}{n_{W I G 20}}+\frac{v_{m W I G 40}}{n_{m W I G 40}}}}
$$


where: $d$ means the average differences between the daily logarithmic rates of return on futures contracts and companies included in the base indices for WIG20 and mWIG40. $\mathrm{v}$ means the variance of these differ- ences for both indices, while $\mathrm{n}$ means the numerical strength of the samples in individual cases.

Table 3 presents average statistics concerning both indices.

Table 3. Differences in investments in futures contracts and indices for WIG 20 \& mWIG40

\begin{tabular}{lll}
\hline & WIG20 & mWIG40 \\
\hline Average difference in daily logarithmic yields & $0.0122 \%$ & $0.0044 \%$ \\
Standard deviation of differences and the yield & $0.57 \%$ & $0.84 \%$ \\
Numerical strength of the sample & 3830 & 1346 \\
\hline
\end{tabular}

The $\mathrm{t}$-value calculated using the method presented above amounted to 0.32 , which means that although the difference in the yields was seemingly high $(2.96 \%$ per year), it was still statistically insignificant.

The verification of the significance using the bookstrap method was conducted according to the following procedure:

1. Differences in daily logarithmic yields between the individual futures contracts and the individual stock indices were calculated. For WIG20, the number of differences calculated in this way was 3830 and it amounted to 1346 for mWIG40.

2. 3830 differences from the WIG20 sample and 1346 differences from the mWIG40 sample were drawn with repetitions.

3. The activity in point 2 was repeated 1000 times.

4. The average value was calculated for each of the draws, thus obtaining a sample of 1000 mean values concerning WIG20 and 1000 mean values concerning mWIG40.

5. The $t$ significance and the p-value were calculated according to formula (5):

$$
t=\frac{\overline{D_{W I G 20}}-\overline{D_{m W I G 40}}}{\sqrt{V_{W I G 20}+V_{m W I G 40}}}
$$

where: $D_{\text {WIG20 }}$ and $D_{m \text { WIG } 40}$ means are appropriately mean values from 1000 of mean value trials using the drawn difference distributions, while $V_{\text {WIG20 }}$ and $V_{m \text { - }}$ ${ }_{W I G 40}$ are mean variances of these samples.
The histogram of the drawn mean values and the summary of the basic statistics as well as the significance calculation are presented in Figure 7 and Table 4 , respectively.

The bookstrap method confirmed previous suppositions about the lack of significance, despite the seemingly significant difference. It can be supposed that the possible increase in the significance would require an examination of a longer period of time for yields, which, unfortunately, is not possible now.

\subsection{Hypothesis IV: the base level in the stock fu- tures market is positively correlated with future yields achieved by long position holders}

Hypothesis IV was examined in an analogous way to the verification of Hypothesis I; the only difference being the use of yields on the investment strategy into futures contracts involving WIG20 and mWIG4 described in the part devoted to Hypothesis II instead of yields on the WIG20 and mWIG40 indexes. The remaining parameters, such as the data sample or the method, remained the same.

Figures 8 and 9 present correlation coefficients between the current base level and various lengths of yields on strategies based on futures contracts.

A high level of correlation was possible for both WIG20 and mWIG40 indices. It was statistically significant for WIG20 at the 5\% level for correlation on 1-session to 155 -session correlations, while for mWIG40, the level was statistically significant for 1-session to 82-session correlations. 
Figure 7. Histogram of the mean value draws for the bookstrap purposes for WIG20 and mWIG40

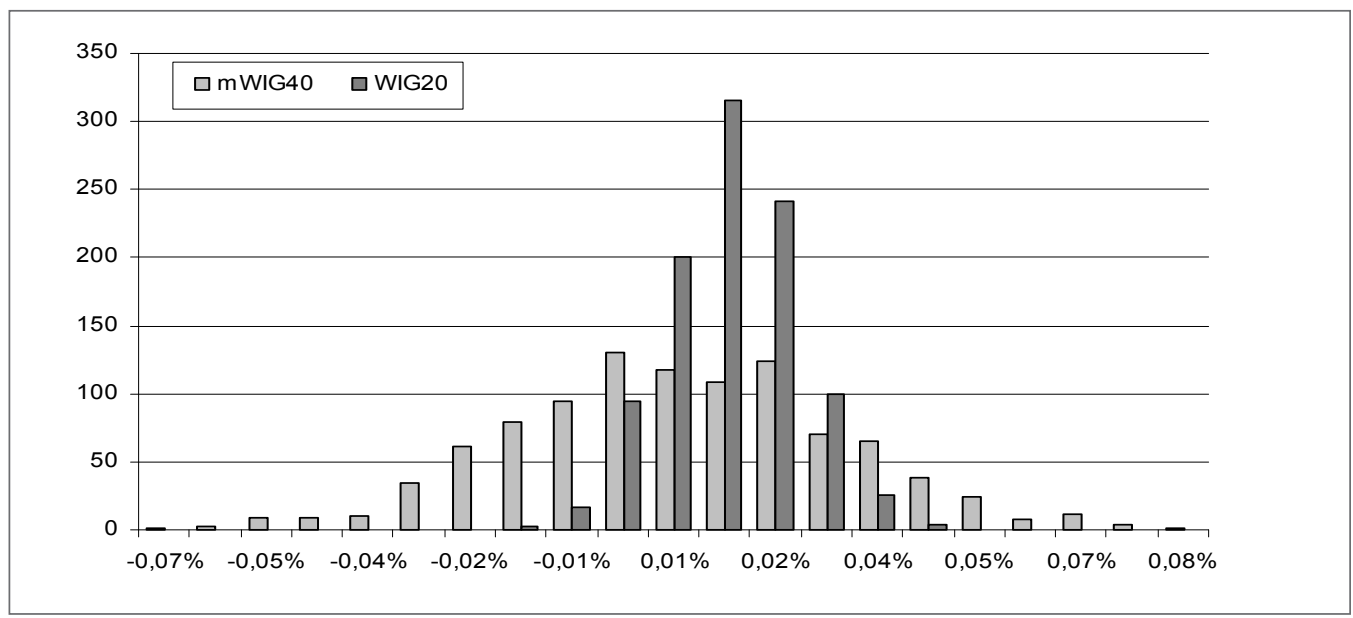

Table 4. Basic statistics of mean value distributions

\begin{tabular}{|c|c|c|c|}
\hline & WIG20 & & mWIG40 \\
\hline Mean value & $0.0125 \%$ & $0.0055 \%$ & $0.0044 \%$ \\
\hline Standard deviation & $0.0095 \%$ & $0.0239 \%$ & $0.84 \%$ \\
\hline t-stat. & 0.27 & & 1346 \\
\hline$p$-value & $29.10 \%$ & & \\
\hline
\end{tabular}

Figure 8. Correlation between the base value of WIG20 and the future yield on futures contract deposits based on this index (February 2000 - July 2010)

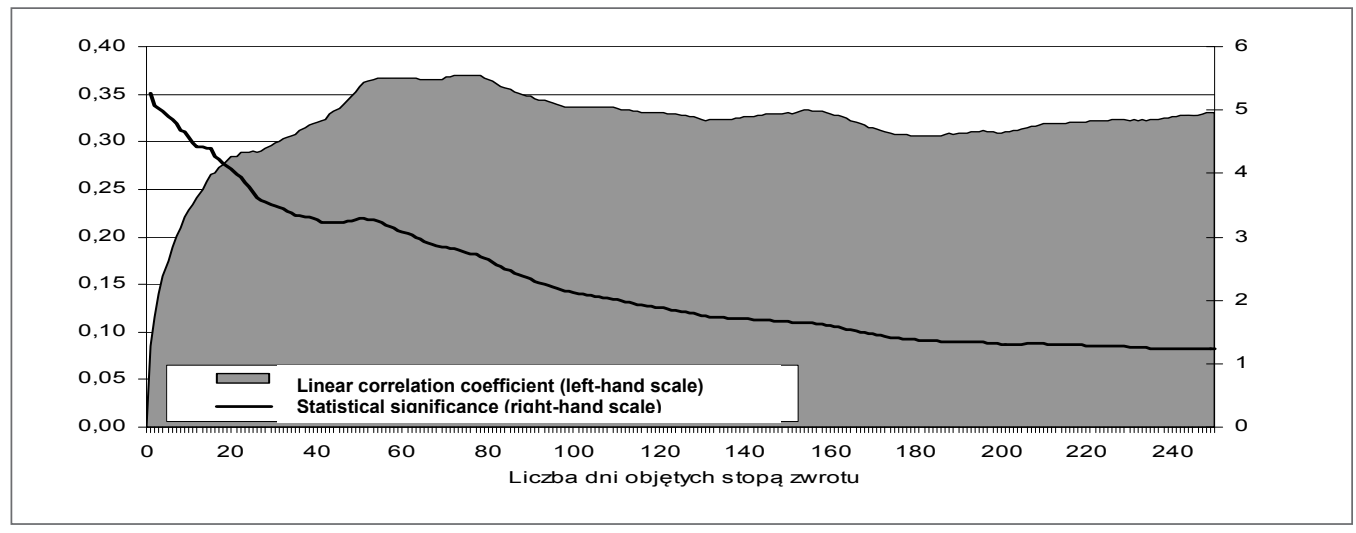

Source: own study 
Figure 9. Correlation between the base value of $\mathrm{mWIG} 40$ and the future yield on futures contract deposits based on this index (November 2006 - July 2010)

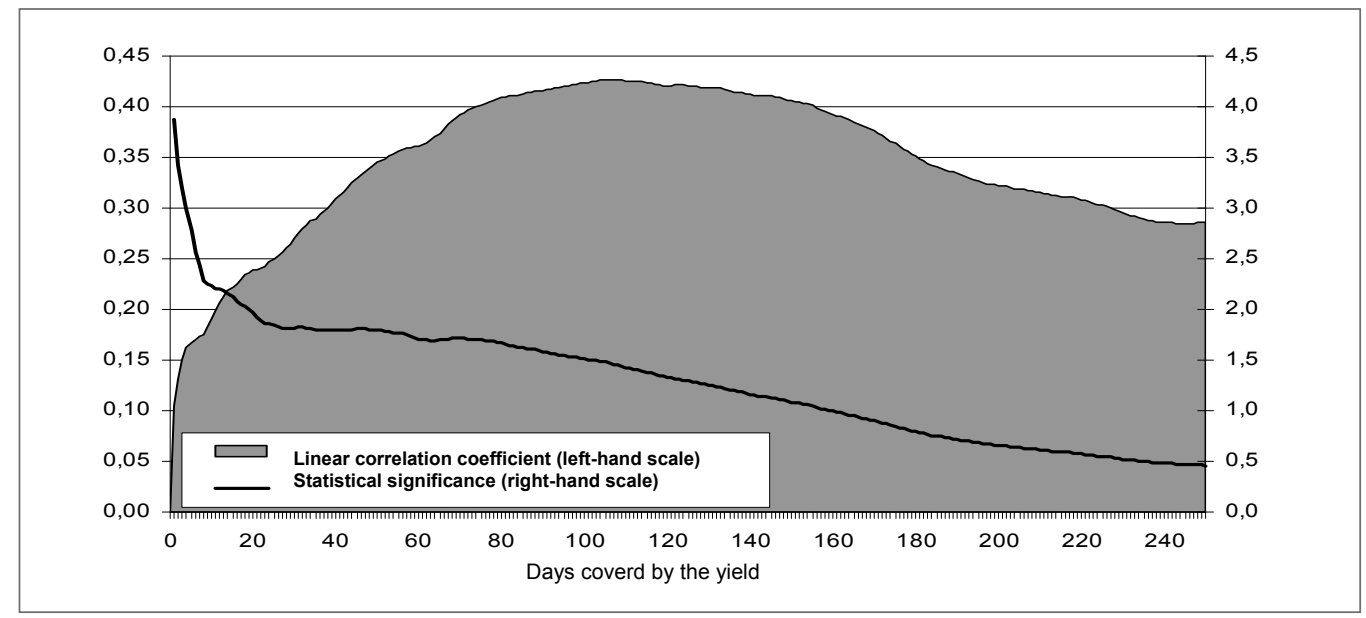

Source: own study

What is interesting, the correlation between the yields on investments into futures contracts turned out to be significantly higher than correlation with the base indices on their own. These findings are presented in Figures 10 and 11.

Figure 10. Correlation of the base level with the WIG20 index and futures contracts - a comparison

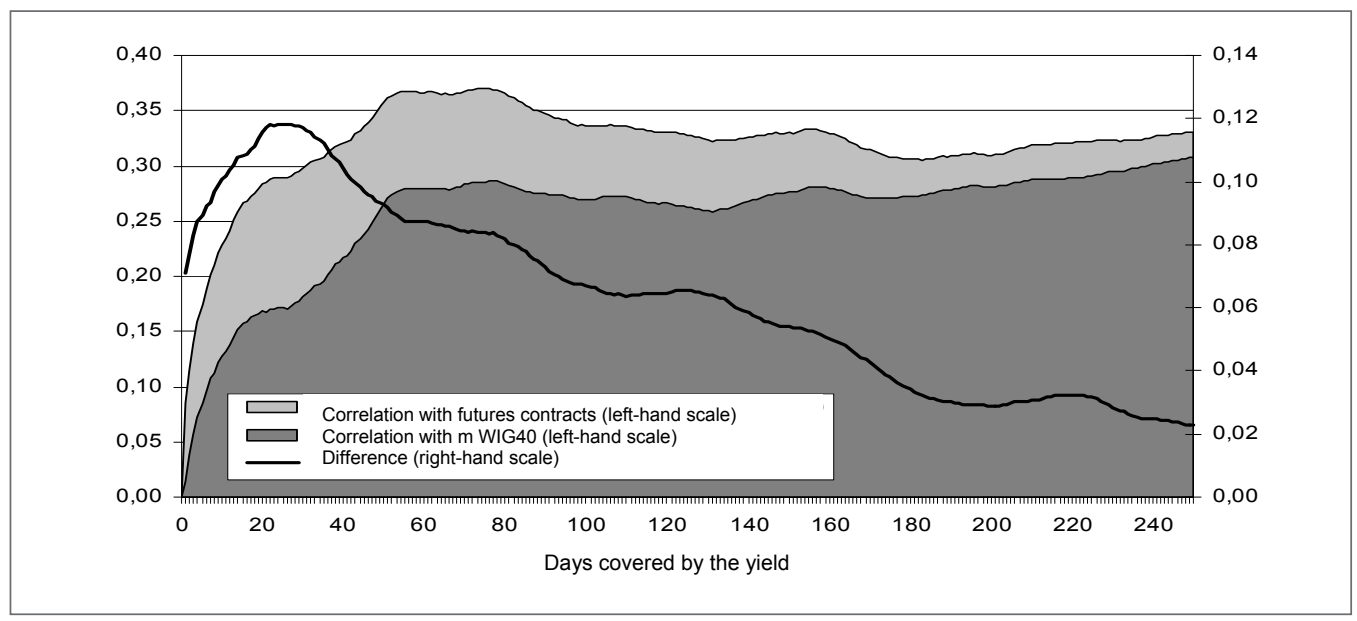

Source: own study 
Figure 11. Correlation of the base level with the mWIG40 index and futures contracts - a comparison

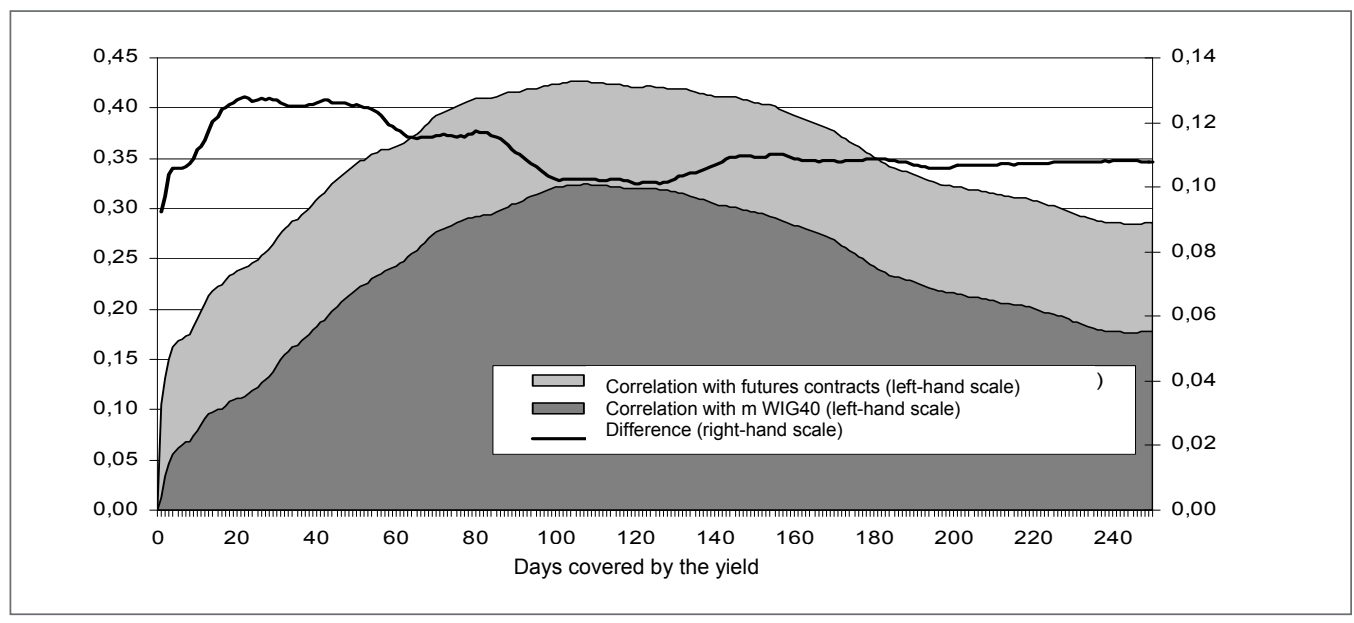

Source: own study

The difference in correlations is quite significant and it can be seen even more clearly when we look at the distribution of the rates of return for individual base levels. The next two figures - 12 and 13 - show the distribution of yields on futures contracts and in- dices for various base variants. The focus was on such yields for both indices, for which the correlation of the contract market with the base level is the highest. This means 75-day yields for WIG20 and 107-day yields for mWIG40.

Figure 12. Distribution on yields on the WIG20 index and contracts based on this index according to the initial base level

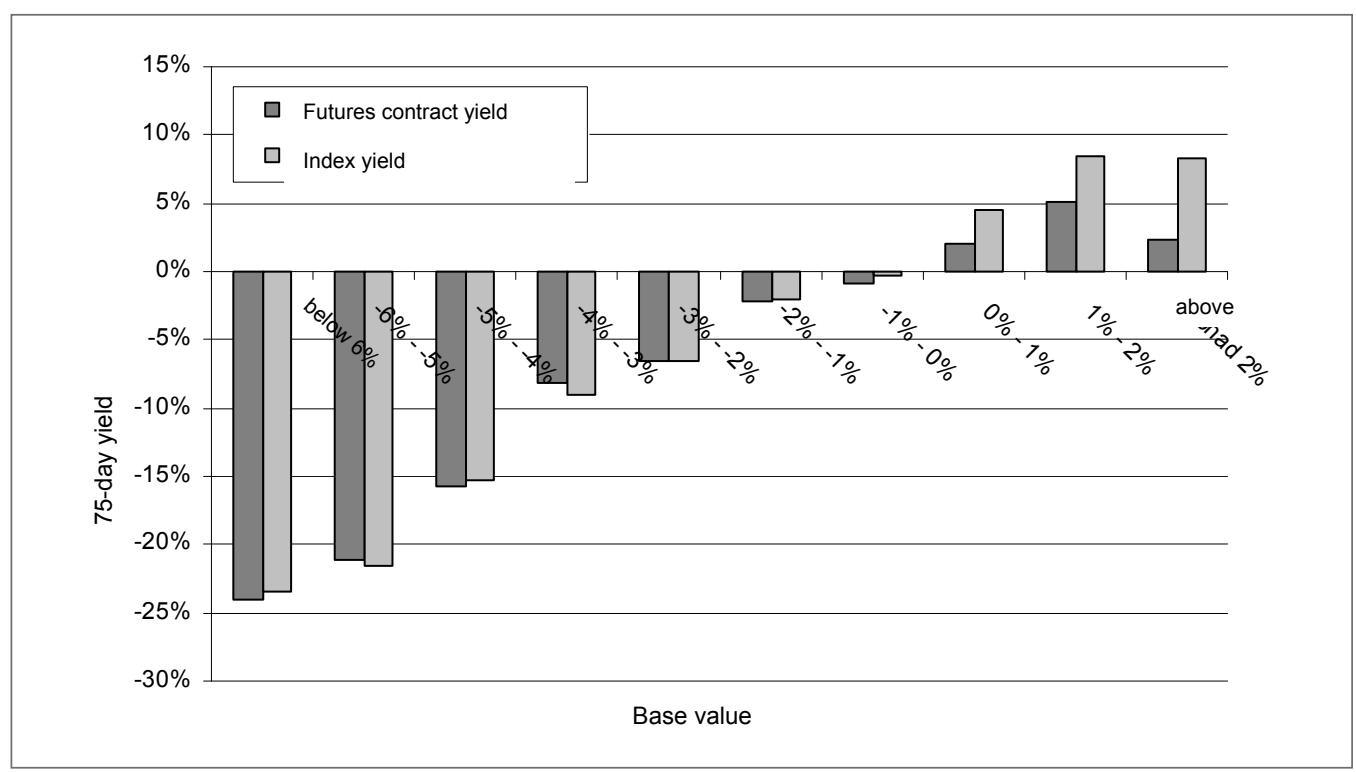


Figure 13. Distribution on yields on the mWIG40 index and contracts based on this index according to the initial base level

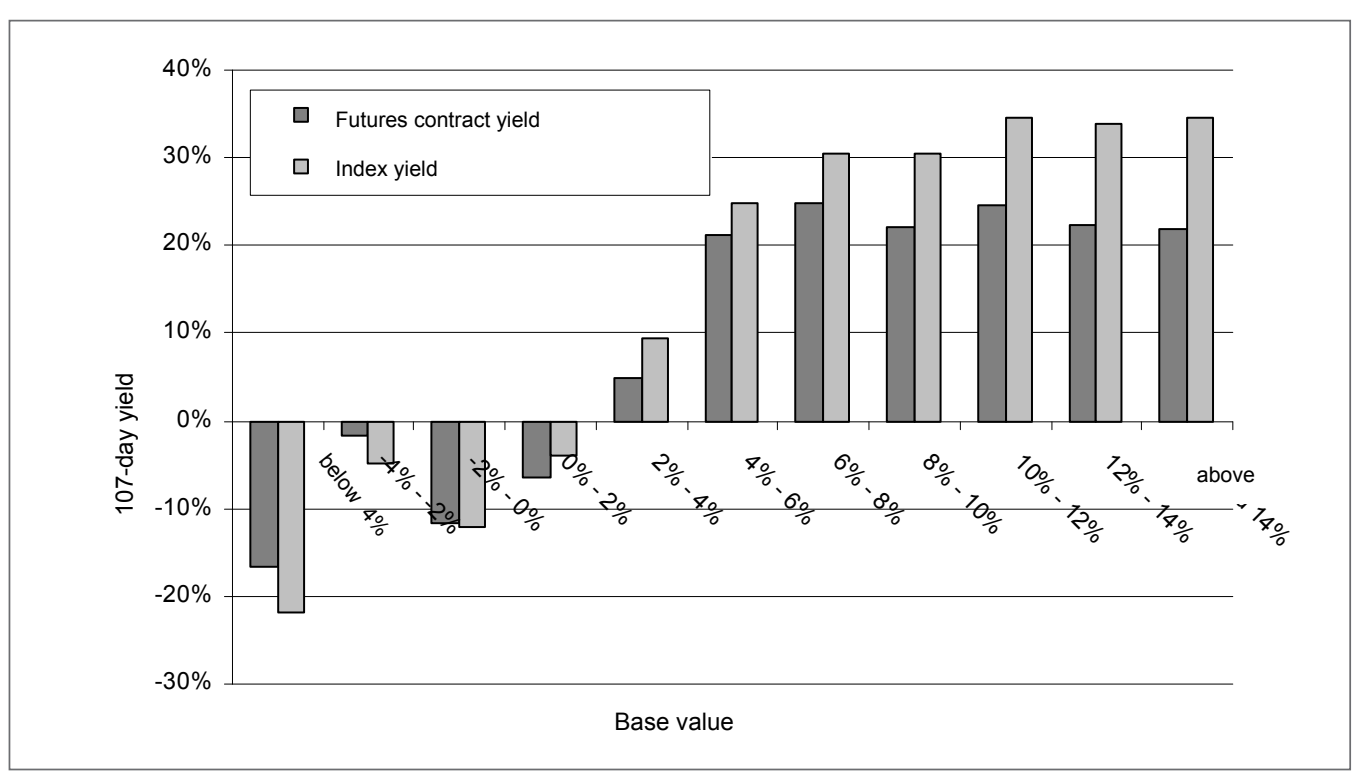

Source: own study

Drawings 12 and 13 confirm the previous observation that the base level proved more effective in forecasting yields on futures contracts than on the index itself. After periods of the positive base, the yields on contracts were usually higher than those on the indices. Analogous dependence, albeit less distinct, can also be noticed in the opposite direction. After periods of the negative base, the yields on futures contracts were often more negative than those on the indices.

On the basis of the afore-mentioned observations, one can be tempted to conclude that the assessment of futures contracts, and therefore, also the base level, includes two components: one expressing "irrational" expectations of market participants concerning the future price level, while the other being the result of the hedging pressure. It seems that both are a source of positive correlation between yields on futures contracts and the base level. The factor connected with the hedging pressure directly affects the yields, for example, by lowering the valuation of futures contracts. The factor connected with market expectations has an indirect impact, as it results in the low futures valuation in periods preceding price depreciation.

\subsection{Hypothesis V: the amount of the risk pre-} mium in the futures market decreases with the increase in the maturity of the financial market Hypothesis V was verified on the basis of WIG20 futures contracts, as they only made it possible to build a time period of sufficient duration. The period under analysis was divided into two equal parts: the period from February 2000 to April 2005 and the period from May 2005 to July 2010. Next, the significance of the difference in the average premium for investments in futures contracts in both periods. The statistical significance was verified using two methods: parametric - assuming normal distribution of the logarithmic differences in yields between contracts and base indices and the bootstrap method, which did not require making assumptions concerning the distribution.

The significance was tested according to formula (6) using the first of the methods presented above:

$$
t=\frac{\overline{d_{0}}-\overline{d_{1}}}{\sqrt{\frac{v_{0}}{n_{0}}+\frac{v_{1}}{n_{1}}}}
$$


where: $d$ means the average differences between the daily logarithmic rates of return on futures contracts in the first and the second periods, $\mathrm{v}$ means the variance of these differences for both indexes, while $n$ means the numerical strength of the samples in individual cases.
Subscripts 0 and 1 refer to the data from the period from February 2000 to April 2005 and the period from May 2005 to July 2010, respectively. Table 5 presents basic statistics concerning both periods.

Table 5. Differences in investments in WIG20 futures contracts and indices for subperiods from February 2000 to April 2005 and from May 2005 to July 2010

\begin{tabular}{lll}
\hline & Period from Feb. 2000 to April 2005 & Period from May 2005 to July 2010 \\
\hline Mean value & $0.0198 \%$ & $0.0047 \%$ \\
Standard deviation & $0.5900 \%$ & $0.5460 \%$ \\
Numerical strength of the sample & 1914 & 1916 \\
t-stat & 0.82 & \\
p-value & $20.52 \%$ & \\
\hline
\end{tabular}

The $\mathrm{t}$-value calculated using the method presented above amounted to 0.82 , which means that although the difference was noticeable, it was statistically insignificant.

The verification of the significance using the bookstrap method was conducted according to the following procedure:

1. Differences in daily logarithmic yields between the futures contracts and the WIG20 were calculated for both subperiods. The samples consisted of 1914 and 1916.

2. 1914 differences from the earlier sample and 1916 differences from the subsequent sample were drawn with repetitions.

3. The activity in point 2 was repeated 1000 times.

4. The average value was calculated for each of the draws, thus obtaining a sample of 1000 mean values concerning the first subperiod and 1000 mean values concerning the second subperiod.

5. The $t$ significance and the $p$-value were calculated according to formula (7):

$$
t=\frac{\overline{D_{0}}-\overline{D_{1}}}{\sqrt{V_{0}+V_{1}}}
$$

where: $D_{0}$ and $D_{1}$ means are appropriately mean values from 1000 of mean value trials using the drawn difference distributions, while $V_{0}$ and $V_{1}$ are mean variances of these samples.

The histogram of the drawn mean values and the summary of the basic statistics as well as the significance calculation are presented in Figure 14 and Table 6 , respectively.

The bookstrap method did not make it possible to confirm the difference in premiums in both periods.

\section{Conclusions}

The study made it possible to a large extent to confirm that the stock futures market is characterised by a range of features showing clear analogies to raw materials contracts. These analogies are manifested by the existence of a time-variable risk premium which is correlated with the base level in the futures market. Unfortunately, the results of the statistical analysis did not confirm with sufficient strength the dependence between the risk premium level and the degree of market maturity and with the stock market.

The results obtained are quite significant for the management of the investment portfolio. They do not only show additional potential income sources for the 
Figure 14. Histogram of the mean value draws for the bookstrap purposes for the subperiods from February 2000 to April 2005 and from May 2005 to July 2010

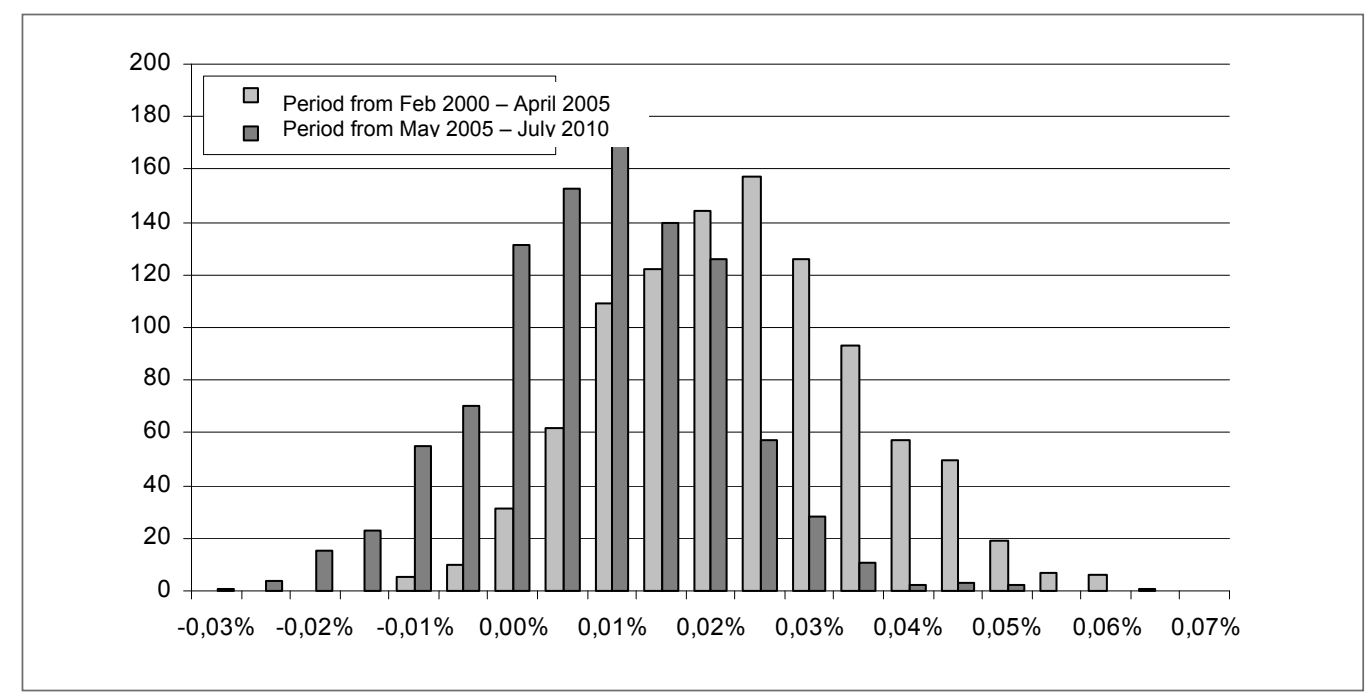

Source: own study

Table 6. Basic statistics of average distributions for the subperiods from February 2000 to April 2005 and from May 2005 to July 2010

\begin{tabular}{lll}
\hline & Period from Feb. 2000 to April 2005 & Period from May 2005 to July 2010 \\
\hline Mean value & $0.0201 \%$ & $0.0045 \%$ \\
Standard deviation & $0.0136 \%$ & $0.0123 \%$ \\
t-stat & 0.85 & 1916 \\
p-value & $19.88 \%$ & \\
\hline
\end{tabular}

investor, but also make it possible to evaluate the costs of portfolio security strategy in a more effective way.

Further research should focus on extending the research sample both in time and space to include other emerging markets with similar legislative regulations.

\section{References}

1. Anson, M. (2000). Handbook of Alternative Assets. Hoboken, New Jersey: John Wiley \& Sons Inc.

2. Scherer, B. \& He, L. (2008). The Diversification Benefits of Commodity Futures Indexes: A MeanVariance Spanning Test. In: F.J. Fabozzi, R. Fuss,
D.G. Kaiser (Eds.), The Handbook of Commodity Investing (pp. 266-310). Hoboken, New Jersey: John Wiley \& Sons Inc.

3. Bessembinder, H. (1992). Systematic risk, hedging pressure and risk premiums in futures markets. Review of Financial Studies, 5(4), 637-667.

4. Black, F. (1976). The pricing of commodity contracts. Journal of Financial Economics, 3, 167-179.

5. Bodie, Z. \& Rosansky, V.I. (1980). Risk and return in commodity futures. Financial Analysts Journal, 36, 27-39.

6. Brennan, M.J. (1991). The Price of Convenience 
and the Valuation of Commodity Contingent Claims. In D. Land, B. Oeksendal (Eds.), Stochastic Models and Options Values, Elsevier Science Publications.

7. Brennan, M.J. (1958). The supply of storage. American Economic Review, 47(1), 50-72.

8. Cootner, P. (1960). Returns to speculators: Telser versus Keynes. Journal of Political Economy, 62, 396-404.

9. De Roon, F., Nijman, T.E. \& Veld, C. (2000). Hedging pressure effects in futures markets. Journal of Finance, 55(3), 1437-1456.

10. Deaves, R. \& Krinsky, I. (1995). Do futures prices for commodities embody risk premiums? Journal of Futures Markets, 15(6), 637-648.

11. Erb, C. \& Harvey, C. (2006). The strategic and tactical value of commodity futures. Financial Analysts Journal 62(2), 69-97.

12. Evans, G. \& Honkapohja, S. (2001). Learning and Expectations in Macroeconomics, Frontiers of Economic Research. Princeton, N.J.: Princeton University Press,

13. Fama, E.F. \& French K.R (1987). Commodity futures prices: Some evidence on forecast power, premiums and the heory of storage. Journal of Business, 60, 55-73.

14. Geman, H. (2005). Commodities and Commodity Derivatives. Chichester: John Wiley \& Sons Inc.

15. Gorton, G. \& Rouwenhorst, G. (2006). Facts and fantasies about commodity futures. Financial Analyst Journal, 62(2), 47-68.

16. Helmuth, J.W. (1981). A report on the systematic bias in live cattle futures prices. Journal of Futures Markets, 1(3), 347-358.

17. Hicks, J.R. (1939). Value and Capital. London: Oxford University Press.

18. Hull, J. (1994). Kontrakty terminowe $i$ opcje. Wprowadzenie. Warsaw: WIG Press.

19. Hurwicz, L. (1946). The theory of the firm and investment. Econometrica, 14(2), 109-136.

20. Kaldor, N. (1939). Speculation and economic theory. Review of Economic Studies, 7, 1-27.

21. Keynes, J.M (1930). A Treatise on Money. (Vol. 2) London: Macmillan.

22. Narang, R.K. (2009). Inside the Black Box. Hoboken, New Jersey: John Wiley \& Sons Inc.

23. Spurgin, R. \& Donohue, M. (2009). Commodities and Managed Futures. In K. Wilkens-Christopher (Ed.), CAIA Level II: Advanced Core Topics in Alternative Investments (pp. 114-214). Hoboken, New Jersey: John Wiley \& Sons Inc.

24. Telser, L. (1958). Futures trading and the storage of cotton and wheat. Journal of Political Economy, 66(3), 233-255.

25. Telser, L. (1960). Reply. Journal of Political Econo$m y, 68,404-415$.

26. Till, H. (2008). Amaranth Lessons Thus Far. Journal of Alternative Investments, 10(4), 82-98.

27. Working, H. (1948). Theory of inverse carrying charge in futures market. Journal of Firm Economics, 30(1), 1-28.

28. Working, H. (1949). The theory of price of storage. American Economic Review, 39(6), 1254-1262.

\section{Notes}

1 Forward curves are understood as curves joining the performance of subsequent futures or forward contracts for each individual settlement period. When this article was written, 4 series of WIG20 futures contracts were listed on the Warsaw Stock Exchange settled every three months. On the other hand, futures contracts on the most popular raw materials listed on commodity exchanges (oil, gold, copper, etc.) usually have over ten or several dozen series settled once a month. This forms more developed structures and shapes of curves - for example - the bumpy shape is characteristic of the oil curve with a growing performance of the closest series and then a falling performance of the more distant series.

2 For 54-day yields the highest local significance level was recorded.

3 This applies to price indices, this group includes both WIG20 and mWIG40.

4 The author would like to thank analysts from the company Expander Doradcy Finansowi for their assistance in constructing the total return indexes.

5 Assuming the normal logarithmic distribution of yields. 